\title{
CHEMOMETRIC OPTIMIZATION OF AN EXTRACTION PROCEDURE USING TARTARIC ACID FOR BUTYLTIN COMPOUNDS FROM SEDIMENT SAMPLES BY GC-PFPD
}

\author{
MANUEL A. BRAVO $a^{*}$, MARCOS FLORES ${ }^{b}$, SONNIA PARRA ${ }^{a}$, WALDO QUIROZ ${ }^{a}$, \\ PAULETTE MAXWELL ${ }^{c}$, ZOLTÁN MESTER ${ }^{c}$ \\ ${ }^{a}$ :Laboratorio de Química Analítica y Ambiental, Instituto de Química, Pontificia Universidad Católica de Valparaíso, Avenida Brasil 2950 Valparaíso, Chile. \\ ${ }^{b}$ : Universidad Santo Tomás, Avenida Carlos Schorr 255 Talca, Chile \\ c: Institute for National Measurement Standard, National Research Council Canada, Ottawa, Ont., Canada K1A OR6
}

\begin{abstract}
In this study a simple extraction procedure was developed to minimize the sulfur interferences on the determination of butyltin in sediment samples based on extraction with tartaric acid solution. The optimal conditions were determined using an experimental design methodology and these were achieved using a solution of tartaric acid $(0.5 \mathrm{M})$ with methanol $(30 \% \mathrm{v} / \mathrm{v})$ for 12 hours in an orbital shaker. This protocol could be followed by a liquid-liquid extraction and this organic phase can be analyzed directly by gas chromatography with pulsed flame photometric detection (GC-PFPD) without any further cleanup due to interferences from elemental sulfur were completely eliminated. The accuracy of the procedure was verified analyzing two reference materials (CRM) (BCR-646, freshwater sediment and PACS-2, marine sediment) and comparing the results to the certified values, the optimized method produced satisfactory results certified values in the CRMs. Finally, harbour sediment samples were analyzed in order to evaluate the suitability of the method for organotin control in complex environmental samples containing high concentrations of sulfur compounds.
\end{abstract}

Keywords: Butyltin extraction; Experimental design; Sulfur interferences; Photometric pulsed flame photometric detection (PFPD)

\section{INTRODUCTION}

Use of organotin compounds (OTC) as fungicides, insecticides, bactericides, wood preservatives and PVC stabilizers lead to their release in the environment. OTCs are present in sewage sludge, water, sediment and soil $[1,2]$. In sediments, these species may originate from the use in antifouling paints [3]. Over the past decades OTC have become of great concern and are now included in the European list of priority pollutants [4]. Their extreme toxicity and severe effects on aquatic organisms as well as humans and their high bioaccumulation potential have led to the need to monitor pollution levels of organotin species, such as butyltin compounds $[5,6]$. Therefore, the development of accurate, selective and sensitive analytical methods for determination of these compounds is of a special importance.

Several methods have been developed for the determination of butyltin in waters, sediments and biological tissues to evaluate the distribution and fate of organotin compounds in the marine environment [7,8,9]. Most of these methods are based on hyphenated techniques using liquid chromatography (LC) and, more frequently, gas chromatography (GC) coupled to selective detectors, such as mass spectrometers (MS) [10], inductively coupled plasma mass spectrometers (ICP-MS) [11], flame photometric detectors [12] and pulsed flame photometric detectors [13]. Many papers have reviewed analytical methods for organotin determination $[14,15]$.

Several extraction techniques have been proposed to achieve better extraction efficiency from solid samples [16]. Non polar solvents such as dichloromethane, pentane, and hexane $[14,17,18]$ or polar solvents such as methanol have been evaluated [15]. However, these methods are limited by a lack of selectivity, i.e., some interferences, such as sulfur species, are coextracted from solid samples. In addition to being ubiquitous in sediment samples, the injection of large amounts of these compounds can lead to overloading of a stationary phase and retention time shifting, resulting in misinterpretation of data even when specific detectors are used $[19,20]$.

Improvements have focused on development of desulfurisation clean-up procedures, including the use of activated copper [21], $\mathrm{AgNO}_{3}$-coated silica gel [22], aluminium oxide [23], silica gel [24], florisil and elemental $\mathrm{Hg}$ [25]. These protocols, however, are an additional step in the analytical procedure increasing analysis time and the potential loss of analyte.

In a previous work, a selective extraction procedure for butytlin determination by GC-MS in sediments using tartaric acid dissolved in a water: methanol mixture assisted with focused microwave have been proposed [27]. In this new work, the extraction procedure was optimized and validated using mechanical agitation and the extract were analyzed by using a less selective detector system such as GC-PFPD. The significant parameters involved in stability of butyltin procedure during extraction and the optimal conditions were evaluated using an experimental design methodology. The results were validated for the analysis of two certified reference material: PACS-2 (marine sediment) and BCR 646 (Estuarine sediment). Finally, the proposed methodology was applied to some harbour sediment samples in order to evaluate the suitability of the method for organotin control in complex environmental samples containing high concentrations of sulfur compounds.

\section{EXPERIMENTAL SECTION}

\subsection{Instrumentation.}

For the analysis of complex sediment and certified reference material (BCR-646, PACS-2) freshwater sediment a Varian 3800 gas chromatograph (Walnut Creek, CA, USA) equipped with a PFPD system and a Varian 1079 split/splitless injector were used. A capillary column SPB-1 (30 m×0.25 mm I.D.; Supelco) was used with nitrogen as carrier gas (flow: $2 \mathrm{ml} \mathrm{min}^{-1}$ ). The chromatographic separation and detection parameters were optimized in a previous study and are described elsewhere [26,27]. A high transmission band filter (320-540 nm; BG 12, Schott, France) was used to observe the emission corresponding to the $\mathrm{Sn}-\mathrm{C}$ emission with a gate delay of $4.0 \mathrm{~ms}$ and a gate width of $2.0 \mathrm{~ms}$.

A mechanical table with elliptic stirring NB-101 M (N-Biotek Inc., Gyeonggi-Do, Korea) was used for the extraction of organotin compounds from sediments and for the derivatization/extraction step.

\subsection{Reagents and Standard Solutions.}

The organotin standards, monobutyltin trichloride (MBT, 95\%), dibutyltin dichloride (DBT, 97\%), tributyltin chloride (TBT, 96\%) and tripropyltin chloride (TPrT, 98\%) were obtained from Sigal (Santiago, Chile). Organotin standard stock solutions (1000 $\mathrm{mg} \mathrm{L}^{-1}$ as $\mathrm{Sn}$ ) were prepared in methanol and kept refrigerated until used. Working standard solutions $\left(5 \mathrm{mg}^{-1}\right)$ were prepared daily from stock standard solutions by dilution in high purity deionized water (DIW) (18M $\Omega$ ) obtained from a Milli-pore system (Milipore, Bedford, MA USA). Glassware was rinsed with deionized water, decontaminated overnight in $10 \%(\mathrm{v} / \mathrm{v})$ nitric acid solution and rinsed again with deionized water.

Methanol, sodium acetate, isooctane, nitric acid, acetic acid, and tartaric acid (TA) were purchased from Merck (Merck Chile, Santiago, Chile). Sodium tetraethylborate $\left(\mathrm{NaBEt}_{4}\right)$ was obtained from Galab products (Geesthacht, Germany). $\mathrm{NaBEt}_{4}$ was dissolved in DIW daily to provide a $2 \%(\mathrm{wt} / \mathrm{v})$ ethylating solution.

\subsection{Analytical Procedures}

2.3.1 Sampling and sample treatment: Sediment samples were collected 
from a harbor in Talcahuano city in southern Chile, where dry-docking and harbor/commercial activities are currently carried out. Surface sediments $(10 \mathrm{~cm}$ depth) were acquired with a Bierge-Ekman dredge $(15 \times 15 \times 15 \mathrm{~cm})$. Approximately $3 \mathrm{~kg}$ of sediment was collected from each site and placed in a polycarbonate bottle. The samples were freeze-dried and and sieved to $1 \mathrm{~mm}$. The fractions $<1 \mathrm{~mm}$ were stored at $-20^{\circ} \mathrm{C}$ prior to analysis.

2.3.2 Extraction of organotin compounds: The extraction procedures were based on tartaric acid optimized extraction conditions. For this purpose, freeze-dried sediment samples were placed in capped $50 \mathrm{~mL}$ polycarbonate tubes and $50 \mu \mathrm{L}$ of a methanolic solution of TPrT ( $10 \mathrm{mg}$ of tin) as internal standard and $19,3 \mathrm{~mL}$ of tartaric acid were added. The mixture was stirred at $420 \mathrm{rpm}$ for $12 \mathrm{~h}$. The extraction solution was collected and immediately placed in a $25 \mathrm{~mL}$ acid cleaned reactor for the ethylation process.

Ethylation was carried out using NaBEt solution $(2 \% \mathrm{w} / \mathrm{v})$ in $0.5 \mathrm{~mol} \mathrm{~L}^{-1}$ sodium acetate/acetic acid buffer ( $\mathrm{pH} 4.8$ ) according to a previously optimized protocol [28].Briefly, $50 \mathrm{~mL}$ of the buffer solution, $500 \mu \mathrm{L}$ of $\mathrm{NaBEt}_{4}$ solution and $1 \mathrm{~mL}$ of isooctane were introduced into the reactor. The mixture was shaken at $400 \mathrm{rpm}$ on an elliptic table for $30 \mathrm{~min}$. Two $\mathrm{mL}$ of the organic phase were removed for analysis by GC-PFPD [26].

A second extraction method, based on a previously optimized glacial acetic acid procedure was also applied to the sediment samples in order to compare the analytical performance [28].

2.3.3 Quantification and validation of the methodology: A standard addition method using (TPrT) as an internal standard (I.S.) was used for OTC quantification in the certified reference materials (CRMs) and real sediment samples.

Validation of the method was performed using two existing CRMs: BCR646 freshwater sediment and PACS-2 marine sediment which contain different certified values for butyl and phenyltin content. All samples were run in triplicate.

2.3.4 Extraction procedure: screening and optimization: Initially, the extraction procedure was studied to evaluate the effect of variables on the extraction process that control the leaching of the analytes from the solid sample. Firstly, a screening of significant factors was carried out by using a fractionated factorial $2^{4-1}$, requiring a total of 16 experiments plus three centers, with a confidence interval of $95 \%$ probability over samples from of marine sediment from the Bay of San Vicente (Chile), previously subjected to a simple extraction procedure. The variables and the levels considered in this screening and optimization study are presented in Table 1. The instrumental response studied was the absolute chromatographic area of each butyltin peak obtained through GC-PFPD following the derivatization process. For optimization process, a central composite design (CCD) has been used. This strategy considers a factorial section ( $2^{4}$ experiments), three center points and 4 axial points (with $\alpha=1.683$,), requiring 23 experiments in all. The selected variables and their levels are presented in Table 1. All the experiments were carried out randomly to minimize the effects of systematic errors.

The Statgraphics Plus 5.0 software package, which provides a flexible, step by step approach, was used for the statistical and mathematical calculations involved in this study.

\section{RESULTS AND DISCUSSION}

\subsection{Sulfur interferences during butyltin analysis}

Interferences due to elemental sulfur $\left(\mathrm{S}^{0}\right)$ occurring during acetic acid extraction of OTC followed by $\mathrm{NaBEt}_{4}$ derivatization and GC-PFPD separation-detection have been reported previously [29]. Fig. 1 shows a typical chromatogram with sulfur interferences labeled $1^{*}, 2^{*}, 3^{*}, 4^{*}, 5^{*}$ and $6^{*}$. According to the literature, these compounds correspond to ethyl-sulfide derivatives formed during the application of the acetic acid extraction protocol $[27,30]$. Based on our experience, reliable results cannot be obtained using these conditions and data misinterpretation can occur even when specific detectors are used. In order to overcome the selectivity problem of PFPD detector a selective extraction procedure will be optimized and applied in real sample analysis.

\subsection{Choice of the variables for chemometric optimization}

Harbor sediment samples are complex matrices which contain sulfur interferences which are evident when the quantification is carried out by GCPFPD [30]. For this reason, the extraction process was optimized using a real sample (SA).
In general, extraction procedures can be affected by several factors, including reagent amount, sample amount, the presence of co-solvents, the extraction system, the presence of chelating agent, volume of extraction solution, temperature, time and $\mathrm{pH}$.

A critical aspect to consider for OTC extraction is the nature of the solvent. A low polarity solvent such as methanol helps the extraction of the triorganotin compounds from solid samples, such as sediment [30] and the use of an aqueous solution avoids the dissolution of elemental sulfur [31]. Several techniques have been evaluated to assist the extraction process, such as microwave and ultrasound radiation and mechanical agitation [32,33,34]. Mechanical agitation was selected in this study, since it is an efficient technique for environmental samples and the organotins are stable during the extraction step. Given that carboxylate groups have been demonstrated to form stable complexes with organotin compounds [35], the addition of tartaric acid to the extractant was evaluated in order to improve recovery of the OTCs. The tartaric acid concentration is a critical parameter in the aqueous-methanol extraction, since TA is less soluble in methanol than in water. Ideally, the TA concentration should be as high as possible, but the methanol content of the extractant limits the TA concentration. The optimum TA concentration will be a compromise between these two considerations.

The results obtained during the screening study by using fractionated factorial experimental design are presented in a Pareto Chart in Fig. 2. It shows that the evaluated factors had a significant effect on the extraction of organotin compounds $(\alpha=0.05)$, since the standardized effect extends beyond the vertical line. However some expected differences were found for mono, di or trisubstituted organotin compounds. These results suggest that a higher $\mathrm{MeOH}$ concentration increased the extraction efficiency of the less polar compounds TBT and DBT, in contrast to the MBT where the higher $\mathrm{MeOH}$ concentration had a negative effect. It is widely recognized that monosubstituted organotin chemistry is very different than that of di and tri organotin compounds [3]. For MBT especially the difficulty of efficient extraction related to the strong adsorption affinity of these compounds in sediment is discussed [36].

In according with results obtained in previous section, all factors studied resulted significant for butyltins. However, in optimization step, this study was focused on TBT because it is associated with more serious environmental concerns than di- and mono substituted organotin compounds. The estimated response surface for the second-order design (Composite central) for TBT shown in Fig. 3 clearly indicates a maximum (curvature on the experimental domain) when the central and axial points are included in the multi-factorial design. The multivariate optimization led to the choice of $19.3 \mathrm{~mL}$ of $0.5 \mathrm{M} \mathrm{TA}$, $30 \% \mathrm{MeOH}$, and $12 \mathrm{~h}$ as the best experimental conditions for the extraction.

\subsection{Analytical performance}

Using the optimized conditions, calibration curves were plotted for each organotin compound in order to compare responses. The limit of the linear response for the optimized method was $1 \mathrm{mg} \mathrm{l}^{-1}$ with correlation coefficients $\left(\mathrm{R}^{2}\right)$ not less than 0.999 for each butyltin and a relative standard deviation of $2-7 \%$ for pure solutions of each analyte. The detection limits achieved for TBT, DBT and MBT were 1.0, 2.5 and $2.5 \mathrm{ng}(\mathrm{Sn}) \mathrm{l}^{-1,}$ respectively, based on a signal-to-noise $(\mathrm{S} / \mathrm{N})$ of three for the lowest detectable concentration. The comparison between the optimized method and a traditional acetic acid method shows that the tartaric acid method is less efficient, however recoveries are sufficient to obtain accurate quantitative results.

\subsubsection{Assessment of the stability of the organotin compounds during} extraction:

Butyltins are moderately stable in most environmental matrices. Halflives are estimated to be from days to several years in sediments [37]. OTC degradation during extraction procedures using carboxylic acid have rarely been studied. In the present study, each OTC was investigated separately and the results show some loss of analyte is possible during manipulation of the samples.

The decrease of the absolute area of butylated species of Sn (IV) at the time, with a marked decrease in the size of signal for TPrT (24 hours), and stability of butylated species of Sn (IV) is presented in Fig. 4. Note that no degradation products were observed when the extraction process was applied to each analyte.

3.3.2 Accuracy of the developed method: Reference materials are powerful tools for quality control measurements. The developed method was applied to the determination of OTC from two existing CRMs which contain different concentrations of OTCs. PACS-2, a highly polluted marine harbour sediment, and BCR-646, a freshwater sediment with intermediate 
contamination, were analyzed using the optimized procedures with LLE-GCPFPD. Table 2 shows that all experimental values (four independent replicates for each sediment) are in good agreement with the certified values.

\subsection{Environmental samples}

Sediment samples with high sulfur interferences collected from a harbor site in Chile are presented in Table 3. Only butyltin compounds were found in the analyzed samples. For TBT and DBT determination this is particularly important because it was only achieved when the proposed method was applied. The use of an extraction solvent containing methanol improved the extraction efficiency of less polar compounds and the high water content inhibits the extraction of sulfur interferences.

\section{CONCLUSIONS}

A simple selective procedure for the liquid-liquid extraction of OTCs from complex sediment was developed. The proposed extraction procedure eliminates the majority of interferences from sulfur and ethylated-sulfur compounds which co-elute with the analytes, seriously impacting the quantification of TBT and DBT in complex samples. The multivariate approach proved to be effective for the optimization of the solid-liquid extraction conditions for butyltin compounds. Besides, analysis of the certified material allowed us to validate the method and to assure the reliability of the proposed analytical procedure. Finally, the proposed methodology appears as a promising alternative to improve selectivity of extraction procedure and PFPD detection for the butyltin determination in complex samples.

\section{ACKNOWLEDGEMENTS}

M. Flores acknowledge the National Scientific Research Committee (Conicyt) for the grant awarded for doctoral studies in Chile. The authors thanks to Fondecyt (project 1120541) for financial support and the Pontificia Universidad Católica de Valparaiso (VIREA-PUCV) for the postdoctoral research fellowship in 2014 to Sonnia Parra.

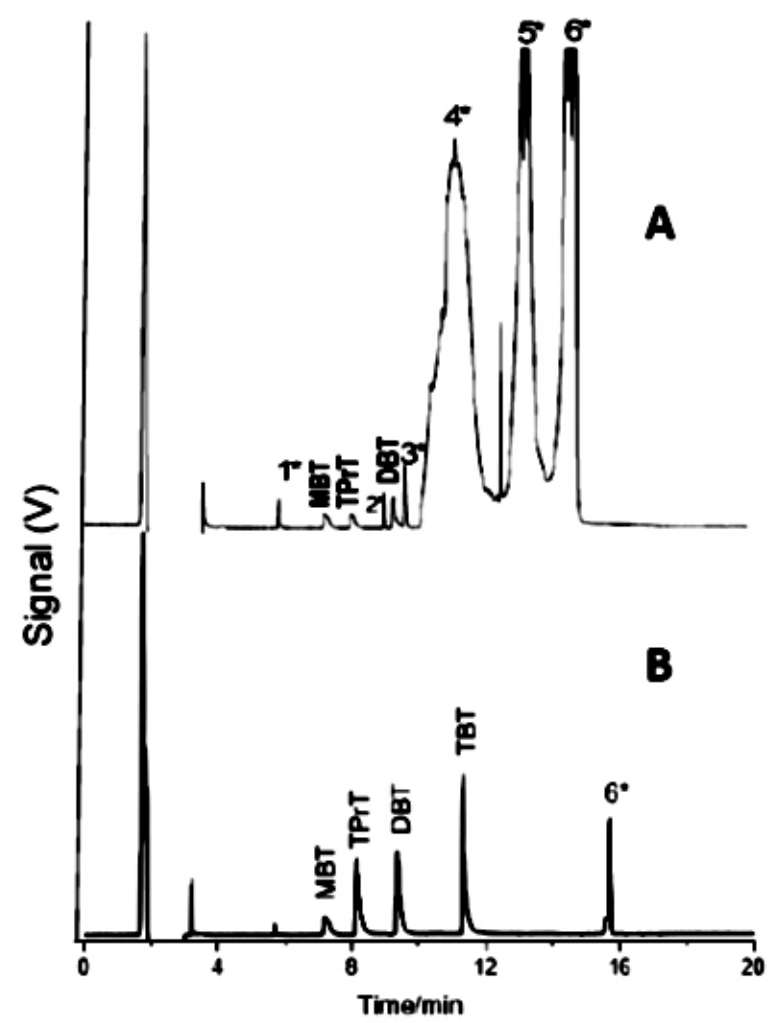

Fig. 1 Typical chromatogram obtained by GC-PFPD of an ethylated acetic acid extract (A) and tartaric acid extract (B) from SA sample.
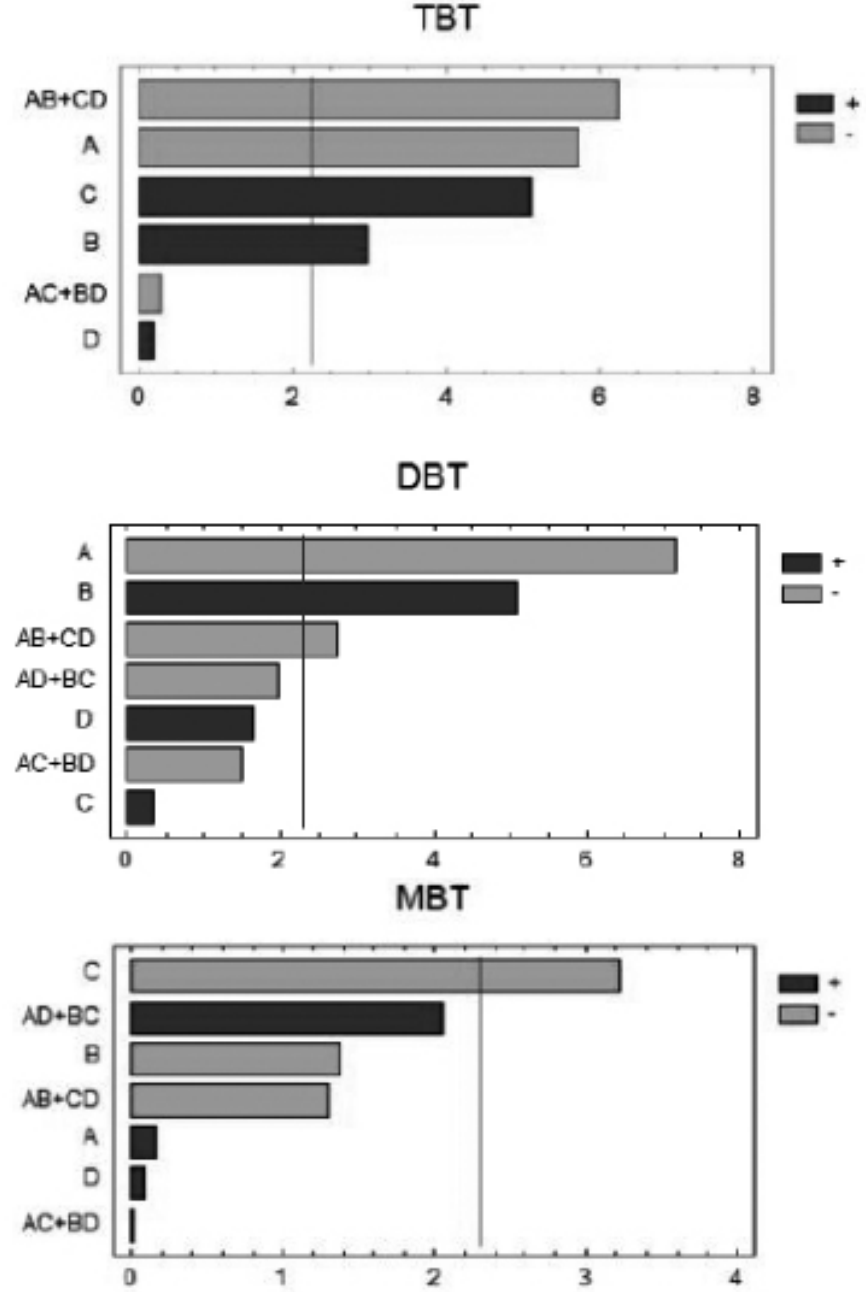

Fig. 2 Pareto chart. Evaluation of significant effects on the extraction of butyltin compounds. A (Mass-solution ratio), B (Concentration of extractant), C (\% methanol), D (Time).

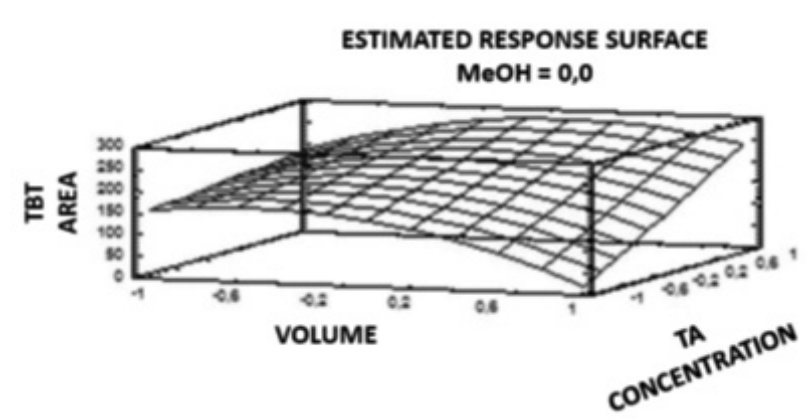

Fig. 3 TBT estimated response surface plot of volume value (in the range $10-30 \mathrm{~mL}$ corresponding to coded values -1 and -1 ) vs TA concentration (in the range $0.1-0.5 \mathrm{M}$, corresponding to coded values -1 and -1 ) considering second level design. 


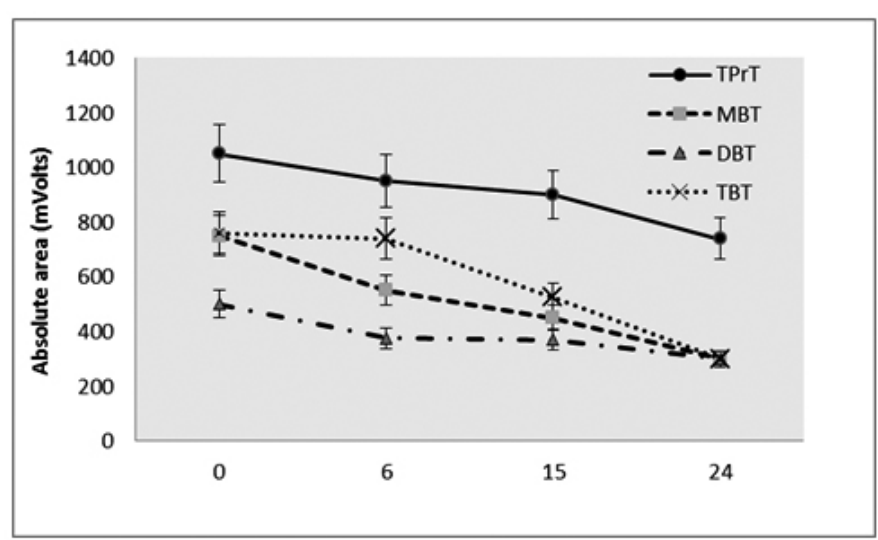
of time

Fig. 4 Absolute area of butylated species stability of Sn (IV) in function

Table 1. Experimental factors and Intervals considered in statistical significance study.

\begin{tabular}{|c|c|c|c|c|}
\hline Factors & $\mathrm{V}(\mathrm{mL})$ & $\mathrm{TA}[\mathrm{M}]$ & $\begin{array}{c}\mathrm{MeOH}(\% \\
\mathrm{v} / \mathrm{v})\end{array}$ & Time $(\mathrm{h})$ \\
\hline Coded factors & $\mathrm{X}_{1}$ & $\mathrm{X}_{2}$ & $\mathrm{X}_{3}$ & $\mathrm{X}_{4}$ \\
\hline Level -1 & 10 & 0.1 & 10 & 6 \\
\hline Center $(0)$ & 20 & 0.3 & 20 & 15 \\
\hline Level +1 & 30 & 0.5 & 30 & 24 \\
$+\alpha$ & 36.8 & 0.6 & 36.8 & 30.1 \\
$-\alpha$ & 3.1 & -0.04 & 3.1 & -0.14 \\
\hline
\end{tabular}

Table 2. Concentration of TBT, DBT and MBT determined in certified reference material $\mathrm{BCR}-646$, freshwater sediment and PACS-2, marine sediment determined by LLE-GC-PFPD (A) y LLE-GC-MS (B).

\begin{tabular}{|c|c|c|c|}
\hline $\begin{array}{c}\text { Concentrations in }[\mathrm{ug}(\mathrm{Sn}) \\
\mathrm{Kg}^{-1}\left(\text { dry mass) } \pm \sigma^{\mathrm{a}}\right]\end{array}$ & MBT & DBT & TBT \\
\hline $\mathrm{A}$ & $395 \pm 68$ & $399 \pm 34$ & $174 \pm 25$ \\
\hline $\mathrm{B}$ & $678 \pm 145$ & $990 \pm 86$ & $808 \pm 77$ \\
\hline $\begin{array}{c}\text { Certified value (BCR- } \\
646)\end{array}$ & $412 \pm 81$ & $393 \pm 46$ & $196 \pm 33$ \\
\hline Certified value (PACS-2) & $600^{\mathrm{b}}$ & $1047 \pm 64$ & $890 \pm 105$ \\
\hline
\end{tabular}

${ }^{a}$ Standard deviation $(n=4)$.

${ }^{\mathrm{b}} \mathrm{C}$ ertified value dediment determined by scarcely .raction Certified value.

Table 3. Butyltin determination in complex sediment samples by the tartaric acid based method.

\begin{tabular}{|c|c|c|c|}
\hline & \multicolumn{3}{|c|}{ Concentration in $\left[\mathrm{ng}(\mathrm{Sn}) \mathrm{Kg}^{-1}\right.$ (dry mass) $\left.\pm \sigma\right]$} \\
\hline Sample & MBT & DBT & TBT \\
\hline SA & $235 \pm 39$ & $177 \pm 37$ & $1178 \pm 32$ \\
\hline S1 & $114 \pm 16$ & $167 \pm 22$ & $276 \pm 34$ \\
\hline
\end{tabular}

\section{REFERENCES}

\section{(Endnotes)}

1.- T. Zuliani, G. Lespes, R. Milacic, J. Scancar, Talanta. 80 (2010) 19451951.

2.- K. Fent, Crit. Rev. Toxicol. 26 (1996) 3.

3.- M. Hoch, Appl. Geochem. 16 (2001) 719.

4.- European Union, Off. J. Eur. Commun. L 129 (1976) 23.

5.- T. Horiguchi, Z. Li, S. Uno, M. Shimizu, H. Shiraishi, M. Morita, J.A.J.

Thompson, C.D. Levings, Mar. Environ. Res. 57 (2003) 75-88.

6.- C. Liscio, M. Di Carro, E. Magi, C.R. Chimie 12 (2009) 831-840.

7.- H. Pinochet, C. Tessini, M. Bravo, W. Quiroz, I. De Gregori, Environ.
Monit. Assess. 155 (2008) 341-353.

8.- R. Morabito, P. Massanisso, P. Quevauviller, Trends Anal. Chem, 19 (2000) 113-119.

9.- G.M.B de la Calle-Guntinàs, R. Scerbo, S. Schiavarini, P. Quevauviller, R. Morabito, Appl. Organomet. Chem. 11 (1997) 693.

10.- A. Stab, U.A.Th. Brinkman, W.P. Cofino, Appl. Organomet. Chem. 8 (1994) 77.

11.- S. Aguerre, G. Lespes, V. Desauziers, M. Potin-Gautier, J. Anal. Atom. Spectrom. 16 (2001) 263.

12.- G. Lespes, V. Desauziers, C. Montigny, M. Potin-Gautier, J. Chromatogr. A 826 (1998) 67-76.

13.- T. Zuliani, G. Lespes, R. Milacic, J. Scancar, M. Potin-Gautier, J. Chromatogr. A 1188 (2008) 281-285.

14.- J. L. Gomez-Ariza, E. Morales, I. Giraldez, D. Sánchez-Rodas, A. Velasco, J. Chromatogr. A 938 (2001) 211.

15.- M. Abalos, J.M. Bayona, R. Compañó, M. Granados, C. Leal, M.D. Prat, J. Chromatogr. A 788 (1997) 1-49.

16.- M. Staniszewska, B. Radke, J. Namièsnik, J. Bolalek, Inter. J. Environ. Anal. Chem. 88(2008)747-774.

17.- M.J.F. Leroy, P. Quevauviller, O.F.X. Donard, M. Astruc, Pure \& Appl. Chem. 70 (1998) 2051.

18.- R. Morabito, in Sample Preparation for Trace Element Analysis, edited by Z. Mester and R. Sturgeon (Elsevier Science, Amsterdam 2003).

19.- I. L. Marr, C. White, D. Ritsau, J.L. Wradell, J. Lomax, Appl. Organomet. Chem. 11 (1997) 11.

20.- M. Bravo, A. Valenzuela, W. Quiroz, M. Pinto, M. Flores, H. Pinochet, Talanta 81(2010)1034-1039.

21.- L.M. Smith, D.L. Stalling, J.L. Johnson, Anal. Chem. 56 (1984) 18301842.

22.- P. Schubert, I. Fernandez-Escobar, E. Rosenberg, J.M. Bayona, J. Chromatogr. A 810 (1998) 245-251.

23.- W.M.R. Dirkx, M.B. De la Calle, M. Ceulemans, F.C. Adams, J. Chromatogr. A 683 (1994) 51

24.- Y.K. Chau, F. Yang, R. J. Maguire, Anal. Chim. Acta 320(1996) 165.

25.- R. Cassi, I. Tolosa, S. De Mora, Mar. Poll. Bull. 56 (2008) 1943-1948.

26.- C. Bancon-Montigny, G. Lespes, M. Potin-Gautier, J. Chromatogr. A $896(2000) 149$

27.- M. Flores, M. Bravo, H. Pinochet, P. Maxwell, Z. Mester, Microchem. J. 98 (2011) 129-134.

28.- C. Carlier Pinasseau, G. Lespes, M. Astruc, Appl. Organomet. Chem. 10 (1996) 505.

29.- M. Bravo, G. Lespes, I. De Gregori, H. Pinochet, M. Potin-Gautier, J. Chromatogr. A 1046 (2004) 217.

30.- F. Smedes, A.S. de Jong, I.M. Davies, J. Environ. Monitor. 2 (2000) 541549.

31.- F. Cotton, G. Wilkinson, Advanced Inorganic Chemistry, Fifth Edition. (1999) 258-308

32.- J. Szpunar, V.O. Schmidtt, R. Lobinski, J. Anal. At. Spectrom. 11(1996)193199.

33.- M. Gallego-Gallegos, M. Liva, R. Muñoz, C. Cámara, J. Chromatogr. A 1114 (2006) 82-88.

34.- E. D. Burton, I.R. Phillips, D.W Hawker, Chemosphere 59 (2005) 585592.

35.- C.G. Arnold, A. Ciani, S.R. Müller, A. Amirbahman, R.P. Schwarzenbach, Environ Sci Technol 32 (1998) 2976-2983.

36.- M. Ceulemans, F. Adams. Anal. Chim. Acta 317 (1995) 161.

37.- M. Abalos, J.M. Bayona, P. Quevauviller, Applied. Organomet. Chem. 12 (1998) 541-549. 